\title{
OPEN ACCESS (OA) FOLKLOR LISAN DI PERPUSTAKAAN KHUSUS
}

\author{
Evi Nursanti Rukmana ${ }^{1 *}$, Kusnandar ${ }^{2}$, Wina Erwina ${ }^{3}$, and Samson CMS $^{4}$ \\ ${ }^{1,2,3,4}$ Program Studi Perpustakaan dan Sains Informasi UNPAD \\ *Correspondence: evi.nursanti.r@gmail.com
}

\begin{abstract}
Open Access $(\mathrm{OA})$ is a digital library service concept that distributes a whole library collection. A special library of oral folklore can provide oral folklore collections through OA services to the community or society. The purpose of this research is to know how the application of oral folklore OA in special libraries. The research method uses descriptive qualitative through literature studies. The author collects, sorts, and analyzes references according to oral folklore studies and OA that come from books, journals, and the internet. The results showed that librarians in special libraries can look for oral folklore in the community or society through cultural documentation and research activities. Cultural documentation is the activity of searching, collecting data, recording, and storing in various media, while research is a structured observation process in oral folklore. The results of cultural documentation and oral folklore then become a special collection of special libraries that can be shared openly to the community or society. So, librarians design Library Management Systems (LMS) and formulate policies in implementing OA. In addition, librarians also organize activities to share information on oral folklore through social media settings, the internet, library websites, and organize Search Engine Optimization (SEO). The conclusion of this research is that OA services can be implemented in special libraries through good cooperation between librarians and the community or society.
\end{abstract}

\begin{abstract}
ABSTRAK
Open Access (OA) adalah konsep layanan perpustakaan digital yang membagikan koleksi perpustakaan secara utuh. Perpustakaan khusus folklor lisan dapat melayankan koleksi folklor lisan melalui layanan OA kepada komunitas atau masyarakat. Tujuan penelitian ini ialah mengetahui bagaimana penerapan OA folklor lisan di perpustakaan khusus. Metode penelitian menggunakan kualitatif deskriptif melalui studi literatur. Penulis mengumpulkan, memilah, dan menganalisis rujukan yang sesuai kajian folklor lisan dan OA yang bersumber dari buku, jurnal, dan internet. Hasil penelitian menunjukkan bahwa pustakawan di perpustakaan khusus dapat mencari folklor lisan pada komunitas atau masyarakat melalui kegiatan dokumentasi budaya dan penelitian. Dokumentasi budaya ialah kegiatan pencarian, pendataan, perekaman, dan penyimpanan dalam berbagai media, sedangkan penelitian adalah proses observasi terstruktur dalam folklor lisan. Hasil dokumentasi budaya dan folklor lisan kemudian menjadi koleksi khas perpustakaan khusus yang dapat dibagikan secara terbuka pada komunitas atau masyarakat. Maka, pustakawan merancang Library Management Systems (LMS) dan menyusun kebijakan dalam penerapan OA. Selain itu, pustakawan pun mengatur kegiatan berbagi informasi folklor lisan melalui pengaturan sosial media, internet, website perpustakaan, dan mengatur Search Engine Optimization (SEO). Simpulan penelitian ialah layanan OA dapat diterapkan di perpustakaan khusus melalui kerja sama yang baik antara pustakawan dan komunitas atau masyarakat.
\end{abstract}

Keywords: Open access; Oral folklore; Special library

\section{PENDAHULUAN}

Open Access (OA) adalah konsep layanan dari sebuah perpustakaan digital, dimana pengguna perpustakaan dapat mengakses koleksi tersebut kapan pun dan di mana pun selama pengguna memiliki akses internet tanpa dipungut biaya oleh pihak pengelola perpustakaan. Pada umumnya, koleksi perpustakaan digital yang menerapkan OA berupa artikel akademik hasil penelitian misalnya jurnal penelitian. Sebelumnya, masih banyak perpustakaan digital atau pun penyelenggara jurnal penelitian yang membatasi akses informasi dengan memungut biaya pada pengguna untuk dapat membaca keseluruhan tulisan artikel penelitian tersebut secara lengkap. Hal tersebutlah yang pada akhirnya memicu adanya gerakan OA di dunia perpustakaan. 
Gerakan OA ditulis Rifai (2017) sebagai gerakan 'open access' yang diinisiasi The Budapest Open Access Initiative and the Bethesda Statement on Open Access Publishing tahun 1990-an. Gerakan ini berawal dari adanya komersialisasi akses artikel dari perpustakaan digital ke pengguna. Pengguna harus mengeluarkan biaya dalam mengakses artikel penelitian yang diperlukannya. Adapun koleksi perpustakaan yang disebarkan secara luas kepada pengguna terdiri dari pelbagai jenis koleksi perpustakaan, di antaranya "artikel jurnal akademik yang telah ditelaah sejawat (peer-review) dan yang belum (preprint/ pracetak/ praterbit), makalah konferensi, tesis, bab buku, dan monograf" (Wikipedia 2019). Jadi, koleksi perpustakaan digital yang disebarluaskan kepada pengguna tidak terpatok artikel penelitian saja. Buku yang sedang proses terbit atau belum diterbitkan, artikel hasil seminar, skripsi, tesis, disertasi, bunga rampai, dan monograf pun dapat disebarluaskan kepada pengguna.

Perpustakaan digital yang melakukan OA pada koleksi perpustakaan telah membantu pengguna dalam hal mengakses informasi secara terbuka, misalnya telah banyak Online Journal Systems (OJS) di Indonesia yang menyediakan artikel jurnal untuk diunduh tanpa menarik bayaran. Namun, bentuk OA sendiri tidak hanya terpaku pada artikel jurnal saja. Koleksi perpustakaan hasil penelitian dalam berbagai bentuk dan tema dapat dibagikan kepada pengguna. Salah satunya adalah koleksi perpustakaan di perpustakaan khusus yang bertemakan budaya.

Perpustakaan khusus merupakan jenis perpustakaan yang memiliki kekhasan dalam koleksinya. Perpustakaan Nasional Republik Indonesia (2017) menyebutkan ada 45 nama perpustakaan khusus dari beberapa lembaga di Indonesia, contohnya Perpustakaan Dinas Kebudayaan dan Pariwisata Provinsi Riau. Data ini belum termasuk perpustakaan khusus bertema budaya yang dikelola secara pribadi atau komunitas. Penulis dapat memperkirakan bahwa di setiap daerah telah memiliki perpustakaan khusus yang koleksinya berisikan budaya dari ciri khas daerahnya masing-masing, misalnya Perpustakaan Rumah Baca Buku Sunda jeung Sajabana di Bandung. Perpustakaan khusus tersebut berfokus menyebarkan pengetahuan budaya dan bahasa Sunda kepada pengguna. Namun demikian, perpustakaan ini belum menerapkan pengelolaan perpustakaan digital. Padahal, koleksi perpustakaan mengenai budaya patut disebarkan kepada pengguna secara luas agar kandungan pengetahuan suatu daerah tidak hilang atau dijiplak oleh negara lain.

Salah satu kajian budaya yang dapat disebarkan kepada pengguna yakni kajian mengenai folklor lisan. Beberapa peneliti sudah mengkaji folklor lisan dari berbagai pandangan bidang ilmu, misalnya bidang bahasa, informasi, perpustakaan, ekonomi, kesehatan, dan lainnya. Namun hasil karya ilmiahnya sendiri masih sedikit diinformasikan kepada pengguna di perpustakaan digital. Padahal berdasarkan UndangUndang Nomor 5 tahun 2017 tentang Pemajuan Kebudayaan, folklor atau tradisi lisan menjadi objek pemajuan kebudayaan pertama. Presiden Republik Indonesia (2017) dalam Pasal 5 (a), menulis bahwa tradisi lisan ialah, "Tuturan yang diwariskan secara turun-temurun oleh masyarakat, antara lain, sejarah lisan, dongeng, rapalan, pantun, dan cerita rakyat." Foklor lisan berasal dari sumber lisan di masyarakat yang memiliki beragam bentuk, misalnya sejarah lisan, dongeng, rapalan, pantun, dan cerita rakyat. Adapun Danandjaja (1994) sendiri membagi folklor lisan menjadi bahasa rakyat, ungkapan tradisional, pertanyaan tradisional, sajak \& puisi rakyat, cerita prosa rakyat, dan nyanyian rakyat. Sesuai kedua rujukan di atas, folklor lisan memiliki jenis yang beragam di daerah Indonesia. Hal ini menambah daftar kekayaan pengetahuan lokal Indonesia untuk dikenalkan pada masyarakat luas.

Adapun beberapa peneliti telah melakukan penelitian folklor lisan, yakni penelitian yang dilakukan Anton and Marwati (2015) mengenai perkawinan di Masyarakat Bajo Pulau Balu Kabupaten Muna Barat. Folklor lisan yang diteliti berupa ungkapan tradisional dalam perkawinan Suku Bajo yang muncul 
pada bagian, “(1) Melamar (massuro), (2) Pertemuan Tokoh Adat (pasitummuang ha'toa ada'), (3) Memanggil secara langsung (pamada'ang), (4) Peminangan (pamassuroang), (5) Pernikahan (panikka'ang), (6) Mengantar Pengantin (malimbah botteh)" (Anton, and Marwati 2015). Setiap prosesi perkawinan menggunakan ungkapan tradisional yang diucapkan pemangku adat. Penelitian ini menyiratkan bahwa makna dalam ungkapan tradisional saat prosesi perkawinan masyarakat adat muncul dari budaya tradisi setempat. Hal ini tersirat makna bahwa sepasang mempelai ketika akan mengarungi bahtera rumah tangga harus menjalankan aturan agama dan lingkungan setempat agar bahagia dan sejahtera. Ungkapan dalam pernikahan dari Masyarakat Bajo tentu akan berbeda dengan ungkapan di masyarakat adat lainnya sesuai bahasa dan budaya yang dianut masyarakatnya.

Selain penelitian di atas, tentu masih banyak lagi penelitian folklor lisan yang belum dikenal masyarakat Indonesia. Hasil penelitian masih tersimpan secara tertutup di perpustakaan atau kalangan pribadi saja. Mengenai hal ini, Fleury dalam Salgues (2018) menulis, "It is good idea to remain attentive to Open Science movements, as well as the publication of raw resulte." Koleksi folklor lisan yang masih disembunyikan di perpustakaan dapat dipublikasikan secara terbuka kepada masyarakat. Walaupun demikian, hasil penelitian yang diterbitkan secara terbuka masih menjadi polemik karena menyangkut hak cipta penulis. Di sisi lain, hasil penelitian yang terpublikasikan secara luas dapat meningkatkan minat baca atau ketertarikan masyarakat dalam kajian tertentu, contohnya folklor lisan. Lebih jelasnya, Wale (2011) menuliskan hasil penelitiannya mengenai peranan Open Access (OA) pada perpustakaan akademik kajian hukum. Perpustakaan tersebut dalam melayankan koleksi bidang hukum menggunakan Integrated Library Systems (ILSs) dan cloud computing. Setiap penelitian mengenai keilmuan bidang hukum disebarkan secara luas sehingga meningkatkan kualitas perpustakaan. Berdasarkan paparan di atas, Open Access (OA) di perpustakaan khusus dapat membantu pengguna dalam mengakses, mengambil, dan menerima koleksi perpustakaan. Pengguna yang dapat mengakses penelitian folklor lisan menjadi tertarik untuk melakukan kajian di daerahnya masing-masing dan mengembangkan budayanya ke luar tanpa takut ditiru oleh pihak luar. Maka, penelitian ini berfokus pada bagaimana Open Access (OA) folklor lisan di perpustakaan khusus.

\section{METODE}

Penelitian mengenai Open Access (OA) folklor lisan di perpustakaan khusus menggunakan metode penelitian kualitatif deskriptif. Peneliti menggambarkan fenomena OA folklor lisan di beberapa perpustakaan khusus. Metode penelitian kualitatif deskriptif digambarkan,

"A research study classified as a descriptive study attempts to describe systematically a situation, problem, phenomenon, service or programme, or provides information about, say, the living conditions of a community, or describes attitudes towards an issue. For example, it may attempt to describe the types of service provided by an organisation, the administrative structure of an organisation, the living conditions of Aboriginal people in the outback, the needs of a community, what it means to go through a divorce, how a child feels living in a house with domestic violence, or the attitudes of employees towards management. The main purpose of such studies is to describe what is prevalent with respect to the issue/problem under study" (Kumar 2011).

Metode penelitian ini menggambarkan fenomena yang sedang dikaji secara berurut atau sistematik. Tujuan penelitian ialah menggambarkan hal yang berhubungan atau terkait dari masalah yang sedang diteliti. Penelitian ini mengkaji fenomena Open Access (OA) folklor lisan di perpustakaan khusus melalui studi literatur. "The literature review is an integral part of the research process and makes a valuable contribution to almost every operational step" (Kumar 2011). Studi literatur menjadi bagian dalam proses penelitian dan memberikan kontribusi yang penting dalam menganalisis fenomena yang sedang dikaji. 
Berdasarkan Kumar (2011) studi literatur bertujuan untuk menajamkan analisis secara teoritis, menjadi penghubung antar konsep yang sedang dibahas, memunculkan temuan hasil analisis, dan mengintegrasikan temuan penelitian dengan teori yang dipilih. Maka, peneliti menggunakan studi literatur dapat memperjelas dan fokus dalam tujuan penelitian dan memperluas kajian mengenai folklor lisan. Adapun tahapan pencarian data dalam menganalisis OA dalam folklor lisan menggunakan beberapa tahapan dari Kumar (2011) di antaranya, "Searching for the existing literature in your area of study, reviewing the selected literature, developing a theoretical framework, and developing a conceptual framework." Pertama, mencari literatur yang sesuai kajian $O A$ dalam foklor lisan dari sumber buku, jurnal, dan internet. Kedua, peneliti mengulas literatur yang telah dipilih. Peneliti mengambil teori folklor lisan dari Danandjaja (1994) dan teori Open Access (OA) dari Crawford (2011). Lalu peneliti mencari rujukan lain untuk menambah analisis penelitian ini. Ketiga, peneliti mengembangkan kerangka teoritis. Teori Danandjaja (1994) dan Crawford (2011) menjadi kerangka acuan analisis fenomena OA dalam folklor lisan di perpustakaan khusus. Keempat, peneliti menggunakan rujukan tambahan dalam merangkai kerangka konseptual.

\section{HASIL DAN PEMBAHASAN}

Perpustakaan khusus di Indonesia merupakan perpustakaan yang memiliki koleksi khusus mengenai kajian tertentu dengan pengguna perpustakaan yang memiliki karakteristik khusus juga, misalnya memiliki minat, pekerjaan, atau pendidikan yang berhubungan dengan koleksi perpustakaan. Berdasarkan rujukan Direktori Perpustakaan Khusus dan Sumber Informasi di Indonesia tahun 2005 dalam penelitian Tambunan (2013) menyatakan bahwa,

"Terdaftar sebanyak 994 perpustakaan yang berdomisili di 32 provinsi (136 kota) di Indonesia. Berdasarkan jumlah tersebut, 668 perpustakaan berada di Pulau Jawa (62 kota), dan sisanya 326 perpustakaan berada di luar Pulau Jawa (74 kota). Perpustakaan khusus terbanyak berdasarkan subjek, yaitu agama (143 perpustakaan) dan ekonomi (140 perpustakaan), kemudian ilmu sosial, pertanian, pendidikan, hukum, dan kedokteran" (Tambunan 2013).

Sesuai rujukan di atas, Indonesia memiliki perpustakaan khusus berjumlah 994 perpustakaan di tahun 2005 yang tersebar di beberapa wilayah. Bidang koleksi perpustakaan yang terbanyak ialah agama dan ekonomi, sedangkan koleksi yang sedikit terdiri dari bidang ilmu sosial, pertanian, pendidikan, hukum, dan kedokteran masih sedikit. Perpustakaan khusus bidang agama menjadi koleksi terbanyak karena sebagian mesjid dan Taman Pendidikan Al-Quran (TPA) telah memiliki perpustakaan. Adapun salah satu bidang ilmu yang masih sedikit dikoleksi perpustakaan khusus yakni bidang ilmu sosial, khususnya mengenai budaya. Padahal sudah banyak para peneliti, akademisi, dan beberapa penulis yang mengkaji budaya namun belum disebarluaskan kepada masyarakat.

Budaya merupakan hasil karya dan karsa manusia dalam kehidupannya sehingga tiap kelompok masyarakat akan memiliki budaya yang berbeda dengan masyarakat lain. Apalagi Indonesia memiliki budaya yang beragam dan hal ini menjadi kekayaan yang tidak terhingga, contohnya budaya folklor lisan sebagai budaya tutur dari sebuah masyarakat. Folklor lisan menjadi tradisi tutur yang sebagian besar masih dimiliki tiap individu atau kelompok berupa pengetahuan tacit, pengetahuan yang belum terdokumentasikan ke dalam berbagai bentuk. Untuk itu, perpustakaan khusus sebagai lembaga informasi dapat mencari, mengumpulkan, dan menyebarluaskan budaya folklor lisan kepada masyarakat melalui Open Access (OA).

Perpustakaan khusus dapat menggunakan layanan OA dalam melayankan koleksi folklor lisan secara utuh tanpa memungut biaya kepada pengguna. Kehadiran layanan OA di perpustakaan khusus tentunya 
menuntut perpustakaan untuk mentransfromasikan diri menjadi perpustakaan digital. Istilah OA sendiri, "Merujuk pada cara akses terhadap informasi, yaitu dengan cara melakukan menghilangkan atau setidaknya mengurangi aspek komersial dari nilai ekonomi suatu informasi" (Rifai 2017). Adanya OA di perpustakaan khusus dapat membantu pengguna menerima informasi dari berbagai media mengenai folklor lisan. Berdasarkan pemaparan ini, OA di perpustakaan khusus memberikan keuntungan dari tersebarkannya koleksi folklor lisan dan meningkatkan peran perpustakaan sebagai lembaga belajar seumur hidup. Maka, peneliti merancang penerapan OA di perpustakaan khusus yang tergambarkan pada gambar 1 di bawah ini.

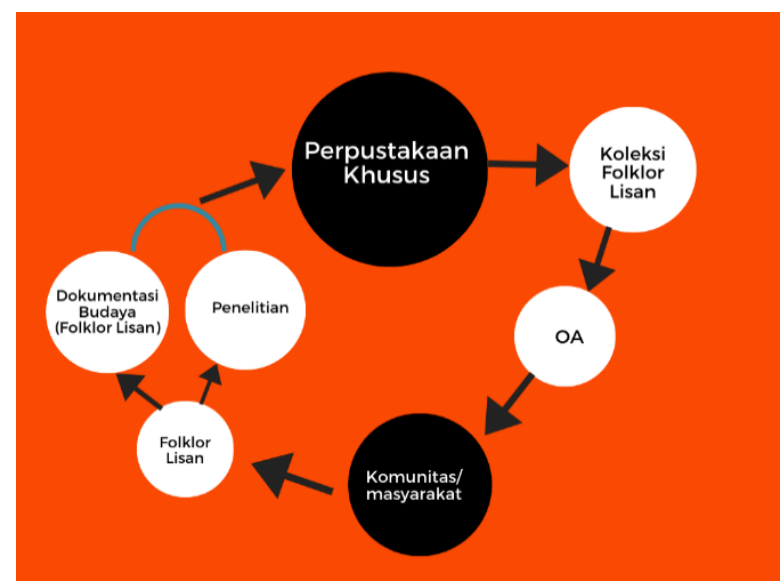

Gambar 1. Kerangka penelitian

(Sumber: Hasil gagasan, 2020)

Sesuai gambar 1, perpustakaan khusus melalui pustakawan mencari, menggali, dan menuliskan data folklor lisan dari komunitas/masyarakat. Folklor lisan yang dicari antara lain bahasa rakyat, ungkapan tradisional, pertanyaan tradisional, sajak \& puisi rakyat, cerita prosa rakyat, dan nyanyian rakyat. Folklor lisan berjenis bahasa rakyat disebut sebagai, logat (dialect) bahasa-bahasa Nusantara, slang, gelar kebangsawanan atau jabatan tradisional, bahasa bertingkat, onomatopoetis, dan onomastis (Danandjaja, 1994). Kata slang ialah kosakata yang digunakan untuk menyamarkan arti bahasa dan bahasa bertingkat yakni bahasa yang digunakan untuk mengingat adanya perbedaan dalam lapisan masyarakat. Kata onomatopoetis ialah kata-kata yang dibentuk dengan mencontoh bunyi atau suara alamiah dan kata onomastis ialah nama tradisional jalan atau tempat-tempat tertentu yang mempunyai legenda sebagai sejarah terbentuknya.

Folklor lisan berjenis ungkapan tradisional terbagi menjadi 4 golongan, diantaranya peribahasa yang sesungguhnya (true proverb), peribahasa yang tidak lengkap kalimatnya (proverbial phrase), peribahasa perumpamaan (proverbial comparison), dan ungkapan-ungkapan yang mirip dengan peribahasa. Brunvand (1968) dalam Danandjaja (1994) membagi ungkapan tradisional atau peribahasa

"Peribahasa yang sesungguhnya adalah ungkapan tradisional yang bersifat kiasan atau ibarat. Peribahasa yang tidak lengkap kalimatnya memiliki sifat kalimatnya tidak lengkap, bentuknya sering berubah, jarang mengungkapkan kebijaksanaan, dan bersifat kiasan. Peribahasa perumpamaan adalah ungkapan tradisional yang dimulai dari kata seperti atau bagai dan lain-lain. Ungkapan yang mirip peribahasa adalah ungkapan yang dipergunakan untuk penghinaan (insult), nyeletuk (retort), atau suatu jawaban pendek, tajam, lucu, dan merupakan peringatan yang dapat menyakitkan hati” (Danandjaja 1994).

Adapun folklor lisan berjenis pertanyaan tradisional disebut sebagai teka-teki, pertanyaan yang bersifat tradisional dan mempunyai jawaban yang tradisional (Danandjaja 1994). Pertanyaan tradisional terbagi 
ke dalam 2 kategori, yakni teka-teki yang tidak bertentangan dan teka-teki yang bertentangan. Teka-teki yang tidak bertentangan dimana jawab dan pertanyaannnya adalah identik, bisa tertebak. Adapun tekateki yang bertentangan memiliki ciri pertentangan antara paling sedikit sepasang unsur pelukisannya.

Folklor lisan berjenis sajak \& puisi rakyat menjadi, "Kesusastraan rakyat yang sudah tertentu bentuknya, biasanya terjadi dari beberapa deret kalimat, ada yang berdasarkan mantra, ada yang berdasarkan panjang pendek suku kata, lemah tekanan suara, atau hanya berdasarkan irama" (Danandjaja 1994). Sajak dan puisi rakyat merupakan bentuk kesusastraan yang kalimatnya sangat terikat dan biasanya memunculkan makna atau pesan bagi kehidupan.

Folklor lisan berjenis cerita prosa rakyat berupa cerita fiksi yang terbagi menjadi 3 golongan, di antaranya mite (myth), legenda (legend), dan dongeng (folktale) (Danandjaja, 1994). "Mite ialah cerita prosa rakyat yang dianggap benar-benar terjadi serta dianggap suci oleh yang empunya cerita. Legenda ialah cerita prosa rakyat yang dianggap oleh empunya cerita sebagai suatu kejadian yang sungguhsungguh pernah terjadi, sedangkan dongeng ialah cerita prosa rakyat yang tidak dianggap benar-benar terjadi” (Danandjaja 1994). Cerita mite, legenda, dongeng merupakan cerita yang terinspirasi dari seluk beluk kehidupan masyarakat dari masa lalu dan masa depan.

Folklor lisan berjenis nyanyian rakyat (folksongs) adalah, "Salah satu genre atau bentuk folklor yang terdiri dari kata-kata dan lagu, yang beredar secara lisan diantara anggota kolektif tertentu, berbentuk tradisional, serta banyak mempunyai varian" (Danandjaja, 1994). Nyanyian rakyat memiliki ciri khas sendiri yakni sifatnya yang mudah berubah-ubah, dari segi bentuk, dan isi yang dapat diubah oleh tiap individu di tiap daerah sehingga bermodel tidak kaku.

Pustakawan setelah mendapatkan data folklor lisan dari masyarakat kemudian melakukan dokumentasi budaya dan penelitian. Dokumentasi budaya dikatakan Kusnandar (2020) sebagai kegiatan pelestarian budaya melalui penyediaan rekaman budaya tak benda (intangible culture) dari suatu suku bangsa untuk menjadi sumber pengetahuan bagi generasi penerus. Folklor lisan merupakan pengetahuan yang masih tersimpan dalam memori tiap individu. Maka, pustakawan perlu mencari, mendata, merekam, dan menuangkannya dalam berbagai media. Apabila folklor lisan di masyarakat Indonesia belum terdata, dikhawatirkan folklor lisan yang ada hilang dan tidak dapat diketahui oleh generasi sekarang atau generasi yang akan datang. Lambat laun, masyarakat di suatu suku bangsa pun mulai tidak mengenali jati dirinya sendiri dan hilanglah kekhasan yang dimiliki daerahnya.

Pustakawan selain melakukan dokumentasi budaya, melakukan atau mengumpulkan penelitian mengenai folklor lisan. Pustakawan saat melakukan dokumentasi budaya dapat sekaligus meneliti mengenai folklor lisan yang sedang dikumpulkan tersebut. Selain itu, pustakawan pun dapat mulai mengumpulkan hasil-hasil penelitian folklor lisan yang dilakukan para peneliti, budayawan, sastrawan, dan penulis. Hasil penelitian folklor lisan tentunya akan menjadi penelitian rujukan bagi penelitian lainnya dan menjadi acuan dalam pengembangan pengetahuan folklor lisan.

Setelah itu, pustakawan menyimpan hasil kegiatan dokumentasi budaya dan penelitian folklor lisan di perpustakaan khusus. Folklor lisan menjadi koleksi khas perpustakaan khusus yang dapat dilayankan kepada komunitas atau masyarakat menggunakan Open Access (OA). Perpustakaan harus menyiapkan perlengkapan dalam menunjang OA yakni pengelolaan Library Management Systems (LMS) dan kebijakan layanan OA. Library Management Systems (LMS) awalnya digunakan dalam pekerjaan pengadaan, pengolahan, pelayanan, dan penyebaran koleksi. Seiring perkembangan teknologi informasi, 
"The LMS systems have evolved with changing library needs, they primarily addressed inventory control needs of print-based resources within the library." (Upasani 2016). LMS berkembang di perpustakaan menjadi sistem yang dapat membantu menemukan koleksi yang dicari pengguna secara cepat dan tepat bernama Open Source Systems. Morgan (2003) dalam Upasani (2016) mengatakan, “The OSS system philosophy outlines the intended use of software and methods for its distribution, while the process focuses on creation and maintenance of software. Typically, the OSS library solutions are freely shared in the public domain." OSS menjadi salah satu bentuk LMS di perpustakaan berupa perangkat lunak dan metode yang digunakan dalam penyebaran koleksi perpustakaan. Pustakawan dapat membagikan informasi mengenai koleksi folklor lisan, mengenalkan perpustakaan (branding), dan mempermudah akses koleksi kepada komunitas atau masyarakat.

Pustakawan setelah menyiapkan perangkat software dalam membagikan koleksi maka mulai menyusun kebijakan dalam menerapkan OA terkait hak cipta. Perpustakaan khusus yang memiliki koleksi folklor lisan berasal dari kegiatan dokumentasi budaya dan penelitian. Hasil dokumentasi budaya dan penelitian yang dilakukan pustakawan tentu dapat dibagikan secara terbuka kepada komunitas atau masyarakat. Namun pustakawan yang mengumpulkan penelitian dari peneliti luar perpustakaan khusus harus mempertimbangkan hak cipta penulis. Pustakawan dapat menghubungi penulis atau peneliti yang bersangkutan untuk mencapai kesepakatan dan kerja sama dalam melakukan OA hasil penelitian. Tentunya, koleksi hasil penelitian yang dipublikasikan merupakan koleksi yang telah disetujui oleh penulis atau peneliti penelitian tersebut. Apabila tidak terjalin kesepakatan, maka perpustakaan khusus tidak berwenang membagikannya secara luas ke komunitas atau masyarakat.

Perpustakaan yang menjalankan OA memiliki komitmen dalam membagikan koleksi perpustakaan secara terbuka dengan rancangan kebijakan yang matang. Suber (2004) dalam Ivwighreghweta and Oghenetega (2012) menyatakan bahwa telah terjadi perubahan pelaksanaan OA.

"Filtering and censorship barriers. Many schools, employers, and governments want to limit what users can see. Language barriers. Most online literature is in English, or just one language, and machine translation is very weak. Handicap access barriers. Most web sites are not yet as accessible to handicapped users as they should be. Connectivity barriers. The digital divide keeps billions of people, including millions of serious scholars, offline."

Rujukan ini menyarankan bahwa perpustakaan harus memiliki alat filter dan sensor dalam mempublikasikan koleksi perpustakaan agar koleksi dapat dimanfaatkan sebaik mungkin oleh komunitas atau masyarakat. OA menjadi gerbang baru perpustakaan khusus dalam mempertahankan perpustakaan sebagai lembaga pengetahuan. Perpustakaan khusus dapat mempertahankan fungsi perpustakaan dalam membagikan koleksi yang dimilikinya untuk dibagikan kepada komunitas atau masyarakat. Berbagi informasi dikatakan sebagai,

"Innovation sharing is a necessity for implementing "co" society, as we have just described it. This sharing is multiple and may assume different ways. In inovations teams, there should be a sufficient dose of information sharing, but not excessively. Too little communication creates clans, clubs, and cliques. In additions, little communication isolate teams. Too much communciation leads to group thinking. This means either adopting the visions of the others, which is generally common and with no future, or choosing ideas created by compititors, as an obscuring smoke cloud, which finaly places the competitors in a more favorable position. Everybody thinks the same, which ultimately decreases originality, and innovation, in the long term" (Salgues, 2018)."

Berbagi inovasi adalah kegiatan memberikan informasi kepada komunitas atau masyarakat yang disebut "co" society. Komunitas atau masyarakat memiliki peran penting dalam terlaksananya OA di 
perpustakaan. Pustakawan mendapatkan data folklor lisan dari komunitas atau masyarakat tersebut. Kemudian pustakawan menyimpan dan menyebarkan hasil dokumentasi budaya dan penelitian folklor lisan kepada komunitas atau masyarakat lagi. Folklor lisan berawal dari komunitas atau masyarakat lalu kembali lagi kepada mereka. Proses penerimaan folklor lisan di komunitas atau masyarakat ini dinamakan berbagi informasi menggunakan sosial media dan internet. Salgues (2018) menyatakan bahwa sosial media menjadi elemen kunci untuk strategis bisnis dan komunikasi, juga sumber informasi. Perpustakaan khusus dapat menjalin komunikasi dengan pihak luar perpustakaan menggunakan sosial media. Selain itu, pustakawan pun dapat membuat komunitas folklor lisan dalam menciptakan dan memberikan kontribusi bagi perpustakaan dari para akademisi, budayawan, sastrawan, penulis, pendongeng, dan kalangan masyarakat lainnya yang tertarik pada kajian folklor lisan.

Pustakawan pun perlu meningkatkan visibilitas rumah digital atau website perpustakaan dalam meningkatkan reputasi perpustakaan dengan mengatur Search Engine Optimization (SEO). SEO adalah, "Upaya mengoptimasi website untuk mendapatkan peringkat teratas di hasil pencarian. Dengan mendapatkan ranking tinggi di hasil pencarian, potensi trafik organik Anda pun meningkat" (Mubarok 2018). SEO website perpustakaan khusus yang baik akan meningkatkan pencarian nama perpustakaan oleh komunitas atau masyarakat di Google. Pengguna yang semakin banyak mencari perpustakaan, maka koleksi perpustakaan folklor lisan pun akan mudah ditemukan.

\section{KESIMPULAN}

Berdasarkan hasil analisis penelitian, pustakawan dapat mencari folklor lisan pada komunitas atau masyarakat melalui kegiatan dokumentasi budaya dan penelitian. Pustakawan mendata koleksi folklor lisan yang terdiri dari bahasa rakyat, ungkapan tradisional, pertanyaan tradisional, sajak dan puisi rakyat, cerita prosa rakyat, dan nyanyian rakyat. Pustakawan menyimpan hasil dokumentasi budaya dan penelitian di perpustakaan khusus sebagai koleksi khas folklor lisan. Perpustakaan kemudian membagikan koleksi folklor lisan kepada komunitas atau masyarakat melalui layanan Open Access (OA). Maka, perpustakaan dalam menerapkan OA harus mempersiapkan Library Management Systems (LMS) dan menentukan kebijakan layanan OA. Selain itu, perpustakaan harus merancang kegiatan berbagi informasi folklor lisan kepada komunitas atau masyarakat melalui sosial media, internet, website, dan pengaturan Search Engine Optimization (SEO).

\section{UCAPAN TERIMA KASIH}

Penulis mengucapkan terima kasih kepada Dr. Dadang Rahmat Hidayat, sebagai Dekan Fakultas Ilmu Komunikasi Unpad, dan Dr. Agus Rusmana, sebagai Ketua Program Studi Perpustakaan dan Sains Informasi Unpad. Kami ucapkan juga kepada pihak yang telah membantu atas terlaksananya artikel ini.

\section{DAFTAR PUSTAKA}

Anton, and Marwati. 2015. "Ungkapan Tradisional Dalam Upacara Adat Perkawinan Masyarakat Bajo Di Pulau Balu Kabupaten Muna Barat.” Jurnal Humanika 15 (3): 1-12. http://ojs.uho.ac.id/index.php/HUMANIKA/article/view/123456/pdf.

Crawford, Walt. 2011. Open Access: What You Need to Know Now. ALA Editions. https://www.alastore.ala.org/content/open-access-what-you-need-know-now.

Danandjaja, James. 1994. Folklor Indonesia: Ilmu Gosip, Dongeng, Dan Lain-Lain. 4th ed. Jakarta: Pustaka Utama Grafiti.

Ivwighreghweta, Oghenetega, and Oghenovo Kelvin Onoriode. 2012. "Open Access and Scholarly Publishing: Opportunities and Challenges to Nigerian Researchers." Chinese Librarianship: An International Electronic Journal 33 (1): 1-13. http://www.white-clouds.com/iclc/cliej/cl33.htm.

Kumar, Ranjit. 2011. Reserach Methodology: A-Step-by-Step Guide for Beginners. 3rd ed. London: Sage Publication Inc. http://www.sociology.kpi.ua/wp-content/uploads/2014/06/Ranjit_KumarResearch_Methodology_A_Step-by-Step_G.pdf. 
Kusnandar. 2020. "Dokumentasi Budaya.” Sumedang.

Mubarok, I. 2018. “Apa Itu SEO? Pengertian, Konsep Dasar, Dan Manfaatnya.” Niaga Hoster Blog. 2018. https://www.niagahoster.co.id/blog/apa-itu-seo/.

Perpustakaan Nasional Republik Indonesia. 2017. "Perpustakaan Khusus." Perpustakaan Nasional Republik Indonesia. 2017. https://www.perpusnas.go.id/directory.php?lang=id\&id=Perpustakaan Khusus.

Presiden Republik Indonesia. 2017. Undang-Undang Republik Indonesia Nomor 5 Tahun 2017 Tentang Pemajuan Kebudayaan. Indonesia. https://kebudayaan.kemdikbud.go.id/wpcontent/uploads/2017/12/Undang-Undang-No-5-Tahun-2017-tentang-Pemajuan-Kebudayaan.pdf.

Rifai, Agus. 2017. “Open Access' Dan Wacana Pengembangan Perpustakaan Akademik Berkelanjutan.” AlMaktabah: Jurnal Komunikasi Dan Informasi Perpustakaan 16 (1): 13-21. http://journal.uinjkt.ac.id/index.php/al-maktabah/article/view/8083/4393.

Salgues, Bruno. 2018. Society 5.0: Industry of the Future, Technologies, Methods, and Tools Volume 1. UK: Jhon Wiley \& Sons.

Tambunan, Komariah. 2013. “Kajian Perpustakaan Khusus Dan Sumber Informasi Di Indonesia.” Baca: Jurnal Dokumentasi Dan Informasi 24 (1): 29-46. https://doi.org/10.14203/j.baca.v34i1.172.

Upasani, Ojaswini Subodh. 2016. "Advantages and Limitations of Open Source Software for Library Management System Functions: The Experience of Libraries in India.” The Serials Librarian: From the Printed Page to the Digital Age 71 (2): 1-10. https://doi.org/10.1080/0361526X.2016.1201786.

Wale, Carla P. 2011. "Cloudy with a Chance of Open Source: Open Source Integrated Library Systems and Cloud Computing in Academic Law Libraries.” Legal Reference Services Quarterly 30 (4): 310-31. https://doi.org/10.1080/0270319X.2011.626324.

Wikipedia. 2019. “Akses Terbuka.” Https://Id.Wikipedia.Org/. 2019. https://id.wikipedia.org/wiki/Akses_terbuka. 